\title{
Ultra-processed foods and added sugars in the Chilean diet (2010)
}

\author{
Gustavo Cediel ${ }^{1,2}$, Marcela Reyes ${ }^{3, *}$, Maria Laura da Costa Louzada ${ }^{1,2}$, \\ Euridice Martinez Steele ${ }^{1,2}$, Carlos A Monteiro ${ }^{1,2}$, Camila Corvalán ${ }^{3}$ and Ricardo Uauy 3,4 \\ 'Department of Nutrition, School of Public Health, University of São Paulo, São Paulo, Brazil: ${ }^{2}$ Center for \\ Epidemiological Studies in Health and Nutrition, University of São Paulo, São Paulo, Brazil: ${ }^{3}$ Institute of Nutrition and \\ Food Technology (INTA), University of Chile, El Libano 5524, Macul, Santiago, Chile: ${ }^{4}$ Department of Nutrition and \\ Public Health Intervention Research, Faculty of Epidemiology and Population Health, London School of Hygiene \\ and Tropical Medicine, London, UK
}

Submitted 30 October 2016: Final revision received 10 April 2017: Accepted 8 May 2017: First published online 19 June 2017

\begin{abstract}
Objective: To assess the consumption of ultra-processed foods and analyse its association with the content of added sugars in the Chilean diet.

Design: Cross-sectional study of national dietary data obtained through $24 \mathrm{~h}$ recalls and classified into food groups according to the extent and purpose of food processing (NOVA classification).

Setting: Chile.

Subjects: A probabilistic sample of 4920 individuals (aged 2 years or above) studied in 2010 by a national dietary survey (Encuesta Nacional de Consumo Alimentario).

Results: Ultra-processed foods represented 28.6 (SE 0.5 ) \% of total energy intake and 58.6 (se 0.9$) \%$ of added sugars intake. The mean percentage of energy from added sugars increased from 7.7 (SE 0.3) to $19 \cdot 7$ (SE 0.5) \% across quintiles of the dietary share of ultra-processed foods. After adjusting for several potential sociodemographic confounders, a 5 percentage point increase in the dietary share of ultra-processed foods determined a 1 percentage point increase in the dietary content of added sugars. Individuals in the highest quintile were three times more likely $(\mathrm{OR}=2 \cdot 9 ; 95 \% \mathrm{CI} 2 \cdot 4,3 \cdot 4)$ to exceed the $10 \%$ upper limit for added sugars recommended by the WHO compared with those in the lowest quintile, after adjusting for sociodemographic variables. This association was strongest among individuals aged $2-19$ years $(\mathrm{OR}=3 \cdot 9 ; 95 \% \mathrm{CI} 2 \cdot 7,5 \cdot 9)$.

Conclusions: In Chile, ultra-processed foods are important contributors to total energy intake and to the consumption of added sugars. Actions aimed at limiting consumption of ultra-processed foods are being implemented as effective ways to achieve WHO dietary recommendations to limit added sugars and processed foods, especially for children and adolescents.
\end{abstract}

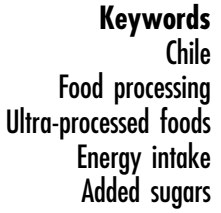

Ultra-processed foods are rapidly dominating the global food system ${ }^{(1)}$. These products are formulated and manufactured industrially employing processes and ingredients not commonly used in traditional culinary preparations $^{(2)}$. Studies from Canada, Brazil and the USA describe these products as being high in energy density and high in free/added sugars content, with low fibre and micronutrient densities, compared with unprocessed or minimally processed foods (even when the latter are combined with salt, sugar or fat used as culinary ingredients) ${ }^{(3-6)}$. Cross-sectional and cohort studies have shown significant positive associations between ultra-processed food consumption and obesity ${ }^{(7-9)}$ and other diet-related non-communicable diseases ${ }^{(10-13)}$.

Several reports have concluded that a high intake of added sugars increases the risk of weight gain ${ }^{(14-17)}$, excess body weight ${ }^{(16)}$, obesity ${ }^{(16-18)}$, type 2 diabetes mellitus ${ }^{(16,18)}$, higher serum TAG $^{(15-17,19)}$, dyslipidaemia $^{(17)}$, high blood cholesterol ${ }^{(18)}$, higher blood pressure $^{(15,17-19)}$, hypertension ${ }^{(16)}$, stroke ${ }^{(16,18)}, \mathrm{CHD}^{(16,18)}$, cancer $^{(16)}$ and dental caries ${ }^{(14-16,18)}$. In fact, the WHO guidelines recommend limiting free sugars intake to less than $10 \%$ of total energy intake to prevent excess body weight and dental caries, and to less than $5 \%$ for 
additional health benefits ${ }^{(14)}$. Free sugars include sugars added to foods by the manufacturer, cook and consumer, plus sugars naturally present in honey, syrups and fruit juices $^{(20)}$. A recent report using nationally representative dietary data from the USA (population aged $>1$ year) showed a strong association between the consumption of ultra-processed foods and the intake of added sugars, suggesting the need to limit consumption of ultraprocessed foods as an effective way of reducing excessive intake of added sugars ${ }^{(21)}$. Yet, these estimates are a 'conservative' way to assess compliance with WHO dietary goals as added sugars include sugars added to foods or beverages during processing, preparation or at the table, but exclude naturally occurring sugars in fruit juices ${ }^{(22)}$.

In Chile, a study based on data collected by a national household food budget survey undertaken in 2006-2007 showed that ultra-processed foods and free sugars represented 52.8 and $16.1 \%$ of total purchased energy, respectively, but no analyses of the association between these two variables were performed ${ }^{(23)}$. Information on the intake of ultra-processed foods and added sugars and on the association between these two variables is particularly relevant in Chile, given the large-scale food policies being implemented in this country such as an increase in taxation of sugar-sweetened beverages and the law regulating food labelling and advertising ${ }^{(24)}$. To address this gap, we used intake data from the most recent national dietary survey undertaken in Chile to assess the consumption of ultra-processed foods and to analyse its association with the dietary content of added sugars.

\section{Methods}

\section{Data source and sampling}

The data were obtained from the National Dietary Survey (Encuesta Nacional de Consumo Alimentario, ENCA) performed between November 2010 and January 2011. The survey used probability sampling by clusters, with stratification and multiple lottery stages, allowing it to represent the Chilean population aged 2 years or above in urban and rural areas of every geographic region: North, Center, South, South (Austral) and Metropolitan. The survey response rate was $85.5 \%$ for a total of 5753 individuals excluding pregnant women and individuals who showed signs of altered mental status. A final sample of 4920 individuals was studied ${ }^{(25)}$.

\section{Dietary intake}

All individuals were eligible for one $24 \mathrm{~h}$ dietary recall interview, conducted using the US Department of Agriculture (USDA) Automated Multiple-Pass Method ${ }^{(26)}$. For children under 12 years of age, an adult caregiver responded the interview. Adolescents aged between 13 and 18 years answered in the presence of the caregiver. Individuals provided information on quantities (using home measurements) and preparation methods of each consumed food item, assisted by a photographic 'atlas' of typical Chilean foods and recipes specifically designed for this survey. Each home measurement was converted to grams or millilitres using a standardized conversion table. All reported values ( $n$ 150156) were double checked and inconsistencies were verified by telephone, resulting in no missing values ${ }^{(25)}$.

\section{Food classification according to processing}

Every reported food item was classified according to the extent and purpose of food processing, following the NOVA procedure ${ }^{(2)}$. Food items were sorted into mutually exclusive food subgroups within: (i) unprocessed or minimally processed foods (eleven subgroups: e.g. fresh meat, roots and tubers, cereals, vegetables, legumes, fruits); (ii) processed culinary ingredients (four subgroups: e.g. plant oils, table sugar, animal fats); (iii) processed foods (five subgroups: e.g. unpackaged fresh bread, cheese, ham and salted meat, vegetables and fruits preserved in brine or sugar syrup); and (iv) ultra-processed foods (seventeen subgroups: e.g. carbonated soft drinks, sweet or savoury snacks, confectionery, industrial desserts, reconstituted meat products, shelf-stable or frozen meals, industrial packaged bread) ${ }^{(2)}$. Details are displayed in Table 1.

\section{Assessing total energy and added sugars intakes}

Energy and total sugars contents of reported food items were calculated using the US Food Composition Table (USDA National Nutrient Database for Standard Reference Release 28$)^{(27)}$. For each reported food item, a USDA food code was assigned, taking into account the nutritional information in the Chilean Food Composition Table ${ }^{(28)}$ and in the Nutrient Fact Panels obtained from Chilean packaged foods (80-120\% agreement in macronutrient and energy contents was required in order to assign a food code). Data on added sugars per food code were obtained by merging the USDA database on added sugars (Food Patterns Equivalents Database 2009-2010) ${ }^{(22)}$. For Chilean food items not found in the USDA database, added sugars were calculated using the algorithm proposed by the nutrient profile model launched by the Pan American Health Organization ${ }^{(29)}$.

\section{Data analysis}

First, we described the contribution of each of the NOVA groups and subgroups to total energy intake and to total added sugars intake for the overall sample. Thereafter, we analysed the average energy contribution of ultraprocessed foods according to sociodemographic variables, namely sex, age group (2-19, 20-49, 50-46, $\geq 65$ years), geographic region (North, Center, South, South (Austral) and Metropolitan), urban or rural setting, family income $(1,2,3-5, \geq 6$ minimum wages) and years of schooling of the head of the family $(\leq 8,9-11, \geq 12$ years $)$, 
using unadjusted and adjusted Gaussian regression analyses. For ordinal sociodemographic variables (age group, family income, years of schooling), tests of linear trend were performed. For categorical variables (sex, geographic region, urban or rural) and ordinal variables with no statistically significant linear trend, Wald tests were used to identify significant differences between categories. Gaussian regression analyses were also used to estimate the association between the dietary contribution of ultraprocessed foods and the dietary content of added sugars (both as proportions of total energy intake). The dietary share of ultra-processed foods was transformed using restricted cubic spline functions with knots at 5th, 27.5th, 50th, $72 \cdot 5$ th and 95 th percentiles, to allow for non-linearity (the Wald test was used to assess non-linearity). We used Poisson regression models to analyse the proportion of individuals consuming more than $5 \%$ and more than $10 \%$ of total energy from added sugars ${ }^{(14,30)}$ across quintiles of the dietary share of ultra-processed foods. We also repeated these analyses stratifying by age group. Regression models evaluating the association between ultra-processed foods and added sugars were adjusted for sociodemographic variables associated with dietary intake of ultra-processed foods. Tests of linear trend were performed to evaluate the effect of quintiles as a single continuous variable. The ENCA sample weights were used in all analyses ${ }^{(25)}$. The Taylor series linearization variance approximation procedure was used for variance estimation in all analyses, in order to account for the complex sample design and the sample weights. Data were analysed using the statistical software package Stata version 14.

\section{Results}

\section{Distribution of total energy intake by food group}

The mean per capita daily energy intake among Chileans aged 2 years or above was $7611 \mathrm{~kJ}$ (1819 kcal). One-third $(33.8 \%)$ of the total energy intake came from unprocessed or minimally processed foods and $11.0 \%$ came from processed culinary ingredients. The remaining energy was nearly equally distributed between processed foods (26.6\%) and ultra-processed foods (28.6\%; Table 1). Within unprocessed or minimally processed foods, meat was the leading contributor ( $7 \cdot 3 \%$ of total energy), followed by roots and tubers, cereals, vegetables, legumes and fruits (each subgroup contributing more than $2 \%$ of total energy intake). Among processed culinary ingredients, plant oils $(6.1 \%)$ and table sugar (4.0\%) were the most consumed; while within processed foods, fresh bread provided the largest contribution to total energy intake $(22.0 \%)$. Among ultra-processed foods energy came from a diverse range of products (seventeen subgroups), led by carbonated soft drinks; cakes, cookies and pies; sauces, dressings and gravies; reconstituted meats; 'milk'-based drinks; 'fruit' drinks/sweetened 'waters'; and salty snacks, each one contributing more than $2.0 \%$ of total energy.

\section{Distribution of energy intake from added sugars by food groups}

The mean per capita daily intake of energy from added sugars was $1017 \mathrm{~kJ}(243.0 \mathrm{kcal})$ or $13.2 \%$ of total energy intake (Table 1). The group of ultra-processed foods contributed more than half of total added sugars consumption (58.6\%) mainly through soft drinks (24.1\%), fruit and water drinks (8.8\%) and cakes, cookies and pies (7.3\%). Processed culinary ingredients contributed 33.6\% of the total added sugars intake, mainly through table sugar consumed as part of home-made drinks, desserts or other preparations. A further $7 \cdot 5 \%$ of total added sugars came from processed foods, mainly from fresh bread (6.3\%).

\section{Intake of ultra-processed foods according to sociodemographic variables}

As shown in Table 2, individuals who were younger, living in urban areas, residing in the metropolitan region and with a higher income presented a significantly higher intake of ultra-processed foods, in both unadjusted and adjusted models. A significant inverse linear trend was observed between age and ultra-processed food consumption, while a significant positive linear trend was observed between family income and consumption of ultra-processed foods. Even though an increased intake of ultra-processed foods was observed among females and heads of families with higher schooling, differences were not statistically significant.

\section{Crude and adjusted associations between dietary share of ultra-processed foods and added sugars intake}

In unadjusted restricted cubic spline Gaussian regression analysis, a direct linear association was found between the dietary share of ultra-processed foods and the dietary content of added sugars (coefficient for linear term $=0 \cdot 22$; 95\% CI 0.08, 0.34; Wald test for linear term, $P=0.001$; Wald test for all non-linear terms, $P=0 \cdot 07$; Fig. 1). The linear association remained fairly unchanged after adjusting for several potential sociodemographic confounders: age, urban or rural setting, geographic region and family income (coefficient for linear term $=0.20 ; 95 \%$ CI $0 \cdot 07$, $0.34)$. Thus, a 5 percentage point increase in the dietary share of ultra-processed foods determined a 1 percentage point increase in the dietary content of added sugars. As shown in Table 3, the dietary content of added sugars increased significantly from $7.7 \%$ in the lowest quintile of the energy contribution of ultra-processed foods to $19.7 \%$ in the highest quintile. After adjusting for potential sociodemographic confounders, individuals in the highest quintile of dietary share of ultra-processed foods had $50 \%$ 
Table 2 Dietary share of ultra-processed foods according to sociodemographic variables in the diet of the Chilean population aged 2 years or above $(2010)^{\star}$

\begin{tabular}{|c|c|c|c|c|c|}
\hline \multirow[b]{2}{*}{ Variable } & \multirow[b]{2}{*}{$n$} & \multicolumn{4}{|c|}{$\%$ of total energy intake from ultra-processed foods } \\
\hline & & Mean & $95 \% \mathrm{Cl}$ & Adjusted mean† & $95 \% \mathrm{Cl}$ \\
\hline \multicolumn{6}{|l|}{ Sex } \\
\hline Women & 2988 & $29 \cdot 1$ & $27 \cdot 9,30 \cdot 4$ & $29 \cdot 4$ & $28 \cdot 1,30 \cdot 6$ \\
\hline Men & 1932 & $28 \cdot 1$ & $26 \cdot 6,29 \cdot 6$ & $27 \cdot 8$ & $26 \cdot 5,29 \cdot 2$ \\
\hline \multicolumn{6}{|l|}{ Age group (years) } \\
\hline $2-19$ & 1374 & $37 \cdot 6$ & $35 \cdot 7,39 \cdot 4$ & $38 \cdot 6$ & $36 \cdot 7,40 \cdot 6$ \\
\hline $20-49$ & 1668 & $27 \cdot 7$ & $26 \cdot 2,29 \cdot 1$ & $26 \cdot 7$ & $25 \cdot 2,28 \cdot 2$ \\
\hline $50-64$ & 948 & $21 \cdot 5$ & $19 \cdot 5,23 \cdot 6$ & $21 \cdot 8$ & $19 \cdot 7,24 \cdot 0$ \\
\hline$\geq 65$ & 930 & $17 \cdot 4 \ddagger$ & $15 \cdot 9,18 \cdot 9$ & 18.3‡ & $16 \cdot 8,19 \cdot 8$ \\
\hline \multicolumn{6}{|l|}{ Residential area } \\
\hline Rural & 610 & $22 \cdot 5^{\mathrm{a}}$ & $20 \cdot 7,24 \cdot 3$ & $23 \cdot 7^{\mathrm{a}}$ & $21 \cdot 9,25 \cdot 5$ \\
\hline Urban & 4310 & $29 \cdot 5^{b}$ & $28 \cdot 4,30 \cdot 6$ & $29 \cdot 3^{b}$ & $28 \cdot 3,30 \cdot 4$ \\
\hline \multicolumn{6}{|l|}{ Geographic region } \\
\hline North & 531 & $27 \cdot 7^{\mathrm{c}}$ & $24 \cdot 7,30 \cdot 7$ & $27 \cdot 5^{\mathrm{c}}$ & $24 \cdot 4,30 \cdot 6$ \\
\hline Center & 1001 & $27 \cdot 8^{\mathrm{C}}$ & $26 \cdot 0,29 \cdot 6$ & $28.5^{\mathrm{c}}$ & $26 \cdot 8,30 \cdot 3$ \\
\hline South & 901 & $25 \cdot 7^{\mathrm{c}}$ & $23 \cdot 7,27 \cdot 7$ & $26 \cdot 7^{\mathrm{c}, \mathrm{d}}$ & $24 \cdot 8,28 \cdot 6$ \\
\hline South (Austral) & 535 & $26 \cdot 6^{\mathrm{c}}$ & $23 \cdot 6,29 \cdot 5$ & $27 \cdot 3^{c}$ & $24 \cdot 2,30 \cdot 4$ \\
\hline Metropolitan & 1952 & $31 \cdot 1^{d}$ & $29 \cdot 4,32 \cdot 8$ & $30 \cdot 2^{\mathrm{c}, \mathrm{e}}$ & $28 \cdot 6,31 \cdot 8$ \\
\hline \multicolumn{6}{|l|}{ Family income } \\
\hline 1 minimum wage & 1019 & $24 \cdot 2$ & $22 \cdot 4,26 \cdot 1$ & $25 \cdot 8$ & $24 \cdot 0,27 \cdot 6$ \\
\hline 2 minimum wages & 1319 & $28 \cdot 8$ & $27 \cdot 2,30 \cdot 4$ & $28 \cdot 7$ & $27 \cdot 2,30 \cdot 3$ \\
\hline 3-5 minimum wages & 871 & $30 \cdot 8$ & $28 \cdot 5,33 \cdot 2$ & $30 \cdot 0$ & $27 \cdot 8,32 \cdot 2$ \\
\hline$\geq 6$ minimum wages & 922 & $30 \cdot 8 \ddagger$ & $28 \cdot 9,32 \cdot 7$ & $30 \cdot 1 \ddagger$ & $28 \cdot 3,31 \cdot 9$ \\
\hline \multicolumn{6}{|c|}{ Years of schooling of head of family } \\
\hline$\leq 8$ years & 2420 & 28.5 & $27 \cdot 0,30 \cdot 1$ & 28.7 & $27 \cdot 3,30 \cdot 1$ \\
\hline $9-11$ years & 1340 & $27 \cdot 6$ & $25 \cdot 8,29 \cdot 3$ & $27 \cdot 4$ & $25 \cdot 7,29 \cdot 1$ \\
\hline$\geq 12$ years & 1160 & 29.9 & $28 \cdot 2,31 \cdot 7$ & $29 \cdot 8$ & $28.0,31 \cdot 6$ \\
\hline Total & 4920 & $28 \cdot 6$ & $27 \cdot 7,29 \cdot 6$ & $28 \cdot 6$ & $27 \cdot 7,29 \cdot 6$ \\
\hline
\end{tabular}

a,b Mean values within the residential area $(a, b)$ or geographic region $(c-e)$ column with unlike superscript letters were significantly different $(P<0.05)$.

${ }^{*}$ National Nutrition Examination Survey 2010, $n 4920$.

†Performed with a multiple linear regression model, averaging or otherwise integrating over the covariates (remaining variables in the table). $\ddagger P \leq 0.001$ for linear trend.

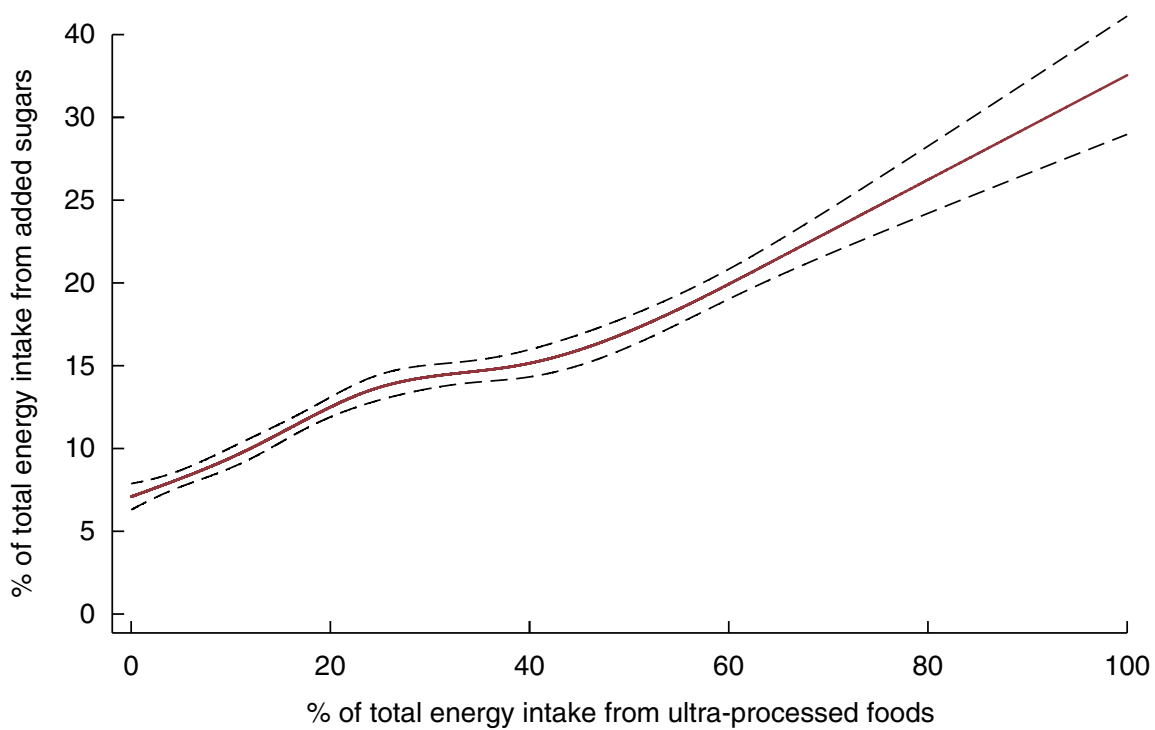

Fig. 1 Association between the dietary share of ultra-processed foods and the dietary content of added sugars in the diet of the Chilean population aged 2 years or above $(2010)^{\star}$ determined by unadjusted restricted cubic spline Gaussian regression analysis $(-$, predicted value; -..--, $95 \%$ Cl). *National Nutrition Examination Survey 2010, n 4920

greater probability of exceeding the $5 \%$ added sugars cut-off compared with those individuals in the lowest quintile (adjusted prevalence ratio $=1 \cdot 5 ; 95 \%$ CI $1 \cdot 4,1 \cdot 6$ ). Similarly, those individuals in the highest quintile of dietary share of ultra-processed foods were three times more likely to exceed the $10 \%$ cut-off compared with those individuals in the lowest quintile (adjusted prevalence ratio $=2 \cdot 9 ; 95 \%$ CI 2.4, 3.4; Table 3). 
Similar associations between the dietary contribution of ultra-processed foods and the dietary content of added sugars were seen in all age groups, being more pronounced among children and adolescents (see online supplementary material, Supplemental Tables 1 to 3). For instance, children and adolescents in the highest quintile of ultra-processed food consumption were four times more likely to exceed the $10 \%$ added sugars cut-off than those in the lowest quintile (adjusted prevalence ratio $=$ $3 \cdot 9 ; 95 \% \mathrm{CI} \cdot 2 \cdot 7,5 \cdot 9)$. The same prevalence ratios were $2 \cdot 7$ (95\% CI $2 \cdot 2,3 \cdot 3)$ among adults and $2 \cdot 3$ (95\% CI $1 \cdot 8,3 \cdot 0)$ among the elderly.

\section{Discussion}

In the Chilean diet, ultra-processed foods provided $28.6 \%$ of total energy intake and contributed more than half of total added sugars intake. A strong association was found between the consumption of these products and the dietary content of added sugars. After adjusting for several potential sociodemographic confounders, a 5 percentage point increase in the dietary share of ultra-processed foods determined a 1 percentage point increase in the dietary content of added sugars. The association between ultraprocessed food consumption and the dietary content of added sugars was present in every age group, being more pronounced among children and adolescents.

The estimated dietary share of ultra-processed foods in Chile in 2010 was similar to that found in Mexico in 2012 (29.8\% of total energy intake; JA Marron, T Sánchez, ML et al., unpublished results), lower than those found in national surveys of industrialized countries such as the USA $(57.9 \%)^{(21)}$ and Canada $(47.7 \%)^{(3)}$, but greater than in Brazil $(21.5 \%)^{(4)}$. A higher share of ultra-processed foods in Chile $(52.8 \%$ of total energy) was estimated for 20062007 by Crovetto et al. ${ }^{(23)}$. Two differences may explain this discrepancy relative to our study: the origin of their estimate was based on household food purchasing data and the fact that all bread was classified as ultra-processed.

As in our study, recent evidence from the USA showed that a 5 percentage point increase in the dietary share of ultra-processed foods determined a 1 percentage point increase in the dietary content of added sugars ${ }^{(21)}$. The US data also showed that the mean percentage of total energy intake from added sugars rose from $7.5 \%$ in the lowest to $19.5 \%$ in the highest quintiles of dietary share of ultraprocessed foods ${ }^{(21)}$. Similar results to our own were obtained by two studies quantifying free sugars. In $\mathrm{Brazil}^{(4)}$, the mean percentage of total energy intake from free sugars increased from $10.9 \%$ in the lowest to $20.2 \%$ in the highest quintiles of dietary share of ultra-processed foods; while in Canada ${ }^{(3)}$, free sugars increased from 7.7 to $19.4 \%$ across these quintiles.

Our study showed that the content of added sugars in the Chilean diet (a total of 81.2 and $57.0 \%$ of all individuals

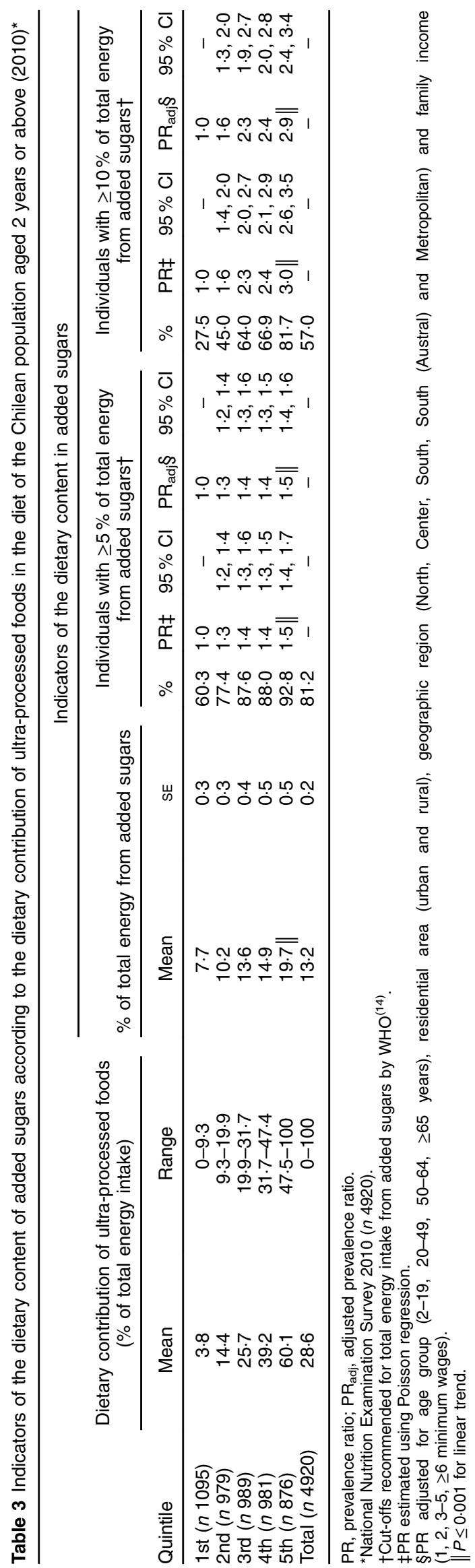


exceeded the 5 and $10 \%$ WHO cut-offs, respectively) was closely associated with the consumption of ultraprocessed food. Indeed, individuals with the highest consumption of ultra-processed foods ( $>47.5 \%$ of energy intake) were three times more likely to exceed the $10 \%$ cut-off compared with those having the lowest consumption $(<9.3 \%$ of energy intake). Even though ultraprocessed food consumption was lower in Chile than in the USA for all quintiles, this prevalence ratio was exactly the same in both countries. Considering the evidence relating consumption of added sugars to risk of chronic diseases ${ }^{(14-19)}$ and the current high prevalence of chronic disease-related risk factors in the Chilean population ${ }^{(31,32)}$, these results have important implications for the public health agenda. This is especially true if we consider the rapid increase in the consumption of selected ultraprocessed foods according to annual national food and drink sales data collected between 1999 and $2013^{(8)}$ and according to household food expenditure data collected in the Santiago metropolitan area between 1986 and $2007^{(33)}$. Furthermore, our results support the regulations recently implemented by the Chilean Government to improve dietary quality, especially those targeting children and adolescents $^{(24,34)}$.

According to our study, almost $70 \%$ of individuals in the lowest quintile of dietary share of ultra-processed foods met the $<10 \%$ cut-off for added sugars, even when the intake of table sugar as culinary ingredient in the Chilean population was comparatively high $(33.5 \%$ of total added sugars intake $v .8 .7 \%$ in the US population). This suggests that in Chile, promoting diets based on unprocessed or minimal processed foods, complemented with small amounts of processed culinary ingredients and processed foods (e.g. fresh bread), as recommended by recently launched food-based dietary guidelines in Brazil ${ }^{(35)}$ and Uruguay $^{(36)}$, would help achieve the WHO added sugars recommendations ${ }^{(14)}$ and the FAO advice for food security $^{(37)}$. Despite the cultural differences, this is also true in countries such as the USA where more than $70 \%$ of individuals in the lowest quintile of dietary share of ultra-processed foods met the $<10 \%$ cut-off for added sugars $^{(21)}$.

The present study is not without limitations. Even though dietary data obtained by $24 \mathrm{~h}$ recalls are imperfect, electronic surveys and the multiple-pass method were used to prevent the interviewer from forgetting items frequently omitted by interviewees ${ }^{(26)}$. In addition, although information indicative of food processing such as place of meals or product brands was collected, these data were missing for some food items and thus may have led to errors in food classification. Since Chile does not have an updated Food Composition Table ${ }^{(28)}$, the intakes of energy and total sugars were calculated using information from the US Food Composition Table (USDA National Nutrient Database for Standard Reference Release 28) ${ }^{(27)}$. For foods lacking information on added sugars, the algorithm proposed in the nutrient profile model launched by the Pan American Health Organization ${ }^{(29)}$ was used. Therefore, the consumption of ultra-processed foods or added sugars could be slightly under- or overestimated. Evidence suggests that some people may under-report consumption of foods with caloric sweeteners ${ }^{(38-40)}$. If so, this bias may lead to underestimation of the overall intake of added sugars or the dietary contribution of ultraprocessed foods, but may less likely affect the association between these variables.

The present study has several strengths. It is based on a large, nationally representative sample of the Chilean population with data on individual consumption rather than on market or household purchases, which do not account for the fraction of wasted food. It is also the first study to examine the contribution of ultra-processed foods to total energy and added sugars intakes in the Chilean diet, providing updated and relevant results for informing the public health agenda. These may also serve as baseline results to measure the impact of a set of regulations being implemented by the Chilean Government aimed at improving diets ${ }^{(24,34)}$.

\section{Conclusions}

We have documented that ultra-processed foods represent close to one-third of total energy intake and contribute more than half of total added sugars in the Chilean diet. Developing strategies to limit and decrease the consumption of ultra-processed foods is a potentially effective way to achieve WHO dietary recommendations on added sugars and to promote eating in accordance with foodbased dietary guidance in Chile, especially for young children and adolescents.

\section{Acknowledgements}

Acknowledgements: The authors thank the Ministry of Health of Chile for supplying the database (Chilean National Dietary Survey, 2010) and the International Development Research Center for its support in obtaining information from Nutrient Fact Panels from packaged foods in 2015. Financial support: The analyses were supported by the Fundaçâo de Amparo à Pesquisa do Estado de São Paulo (FAPESP). G.C. is a beneficiary of a Postdoctoral Fellowship from FAPESP (grant number 2016/13522-3). FAPESP had no role in the design, analysis or writing of this article. Conflict of interest: The authors declare no conflict of interest. Authorship: C.A.M., M.R. and G.C. designed the research. G.C., M.L.d.C.L. and E.M.S. took care of data management and analyses. G.C., M.R., C.C. and R.U. interpreted the data. G.C. and M.R. wrote the first draft of the manuscript. All authors read, edited and approved the final manuscript. Ethics of human subject participation: Verbal consent was formally recorded. 


\section{Supplementary material}

To view supplementary material for this article, please visit https://doi.org/10.1017/S1368980017001161

\section{References}

1. Monteiro CA, Moubarac J-C, Cannon G et al. (2013) Ultraprocessed products are becoming dominant in the global food system. Obes Rev 14, 21-28.

2. Monteiro CA, Cannon G, Levy R et al. (2016) NOVA. The star shines bright. World Nutr 7, 1-3, 28-38.

3. Moubarac J-C, Batal M, Louzada ML et al. (2017) Consumption of ultra-processed foods predicts diet quality in Canada. Appetite 108, 512-520.

4. Louzada ML, Martins A, Canella D et al. (2015) Ultraprocessed foods and the nutritional dietary profile in Brazil. Rev Saude Publica 49, 38.

5. Louzada ML da C, Martins APB, Canella DS et al. (2015) Impact of ultra-processed foods on micronutrient content in the Brazilian diet. Rev Saude Publica 49, 45.

6. Martínez Steele E, Popkin BM, Swinburn B et al. (2017) The share of ultra-processed foods and the overall nutritional quality of diets in the US: evidence from a nationally representative cross-sectional study. Popul Health Metr 15, 6.

7. Canella DS, Levy RB, Martins APB et al. (2014) Ultraprocessed food products and obesity in Brazilian households (2008-2009). PLoS One 9, e92752.

8. Moubarac J-C, Pan American Health Organization \& World Health Organization (2015) Ultra-processed food and drink products in Latin America: trends, impact on obesity, policy implications. http://iris.paho.org/xmlui/bitstream/handle/ 123456789/7699/9789275118641_eng.pdf (accessed July 2016).

9. Mendonça R de D, Pimenta AM, Gea A et al. (2016) Ultraprocessed food consumption and risk of overweight and obesity: the University of Navarra Follow-Up (SUN) cohort study. Am J Clin Nutr 104, 1433-1440.

10. Monteiro CA, Levy RB, Claro RM et al. (2011) Increasing consumption of ultra-processed foods and likely impact on human health: evidence from Brazil. Public Health Nutr 14, 5-13.

11. Rauber F, Campagnolo PDB, Hoffman DJ et al. (2015) Consumption of ultra-processed food products and its effects on children's lipid profiles: a longitudinal study. Nutr Metab Cardiovasc Dis 25, 116-122.

12. Tavares LF, Fonseca SC, Garcia Rosa ML et al. (2012) Relationship between ultra-processed foods and metabolic syndrome in adolescents from a Brazilian Family Doctor Program. Public Health Nutr 15, 82-87.

13. Mendonça R de D, Lopes ACS, Pimenta AM et al. (2017) Ultra-processed food consumption and the incidence of hypertension in a Mediterranean cohort: the Seguimiento Universidad de Navarra Project. Am J Hypertens 30, 358-366.

14. World Health Organization (2015) Guideline: Sugars Intake for Adults and Children. Geneva: WHO; available at http://apps. who.int/iris/bitstream/10665/149782/1/9789241549028_eng.pdf

15. Johnson RK, Appel LJ, Brands M et al. (2009) Dietary sugars intake and cardiovascular health: a scientific statement from the American Heart Association. Circulation 120, 1011-1020.

16. US Department of Health and Human Services \& US Department of Agriculture (2015) Scientific Report of the 2015 Dietary Guidelines Advisory Committee. Washington, DC: USDA; available at https://health.gov/dietaryguidelines/2015scientific-report/PDFs/Scientific-Report-of-the-2015-DietaryGuidelines-Advisory-Committee.pdf
17. Vos MB, Kaar JL, Welsh JA et al. (2016) Added sugars and cardiovascular disease risk in children: a scientific statement from the American Heart Association. Circulation 135, 1-18.

18. Canadian Heart and Stroke Foundation Position Statement (2014) Sugar, Heart Disease and Stroke. Toronto, ON: Canadian Heart and Stroke Foundation; available at http://www.heartandstroke.ca/-/media/pdf-files/canada/2017position-statements/sugar-ps-eng.ashx

19. Kell KP, Cardel MI, Bohan Brown MM et al. (2014) Added sugars in the diet are positively associated with diastolic blood pressure and triglycerides in children. Am J Clin Nutr 100, $46-52$.

20. Cummings JH \& Stephen AM (2007) Carbohydrate terminology and classification. Eur J Clin Nutr 61, Suppl. 1, S5-S18.

21. Martínez Steele E, Baraldi LG, Louzada MLdC et al. (2016) Ultra-processed foods and added sugars in the US diet: evidence from a nationally representative cross-sectional study. BMJ Open 6, e009892.

22. US Department of Agriculture, Agricultural Research Service (2010) Food Patterns Equivalents Database 2009-2010: Methodology and user guide. https://www.ars.usda.gov/ northeast-area/beltsville-md/beltsville-human-nutritionresearch-center/food-surveys-research-group/docs/fpedmethodology/ (accessed October 2016).

23. Crovetto MM, Uauy R, Martins AP et al. (2014) Household availability of ready-to-consume food and drink products in Chile: impact on nutritional quality of the diet. Rev Med Chil 142, 850-858.

24. Corvalán C, Reyes M, Garmendia ML et al. (2013) Structural responses to the obesity and non-communicable diseases epidemic: the Chilean Law of Food Labeling and Advertising. Obes Rev 14, 79-87.

25. Ministerio de Salud, Gobierno de Chile (2010) Encuesta de consumo alimentario en Chile (ENCA). http://web.minsal. cl/enca/ (accessed October 2016).

26. US Department of Agriculture, Agricultural Research Service (2016) Automated Multiple-Pass Method. https://www.ars.usda. gov/northeast-area/beltsville-md/beltsville-human-nutritionresearch-center/food-surveys-research-group/docs/ampm-usdaautomated-multiple-pass-method/ (accessed October 2016).

27. US Department of Agriculture, Agricultural Research Service (2016) USDA National nutrient database for standard reference, release 28. https://ndb.nal.usda.gov/ndb/ (accessed October 2016).

28. Jury G, Urteaga R. C, Taibo M et al. (1997) Porciones de Intercambio y Composición Química de Los Alimentos de la Pirámide Alimentaria Chilena. Santiago: INTA, University of Chile.

29. Pan American Health Organization (2016) Pan American Health Organization Nutrient Profile Model. Washington, DC: PAHO; available at http://iris.paho.org/xmlui/handle/ $123456789 / 18621$

30. Mann J, Cummings JH, Englyst HN et al. (2007) FAO/WHO scientific update on carbohydrates in human nutrition: conclusions. Eur J Clin Nutr 61, Suppl. 1, S132-S137.

31. Araya BM, Padilla O, Garmendia ML et al. (2014) Obesidad en mujeres chilenas en edad fértil. Rev Med Chil 142, 1440-1448.

32. Ministerio de Salud, Gobierno de Chile (2010) Encuesta Nacional de Salud. http://www.minsal.gob.cl/portal/url/ item/9ad9cbfb71ca4705e04001011e010283.pdf (accessed October 2016).

33. Crovetto M \& Uauy R (2012) Changes in processed food expenditure in the population of Metropolitan Santiago in the last twenty years. Rev Med Chil 140, 305-312.

34. Ministerio de Salud, Gobierno de Chile (2016) Ley de Alimentos. http://www.minsal.cl/reglamento-de-la-ley-deetiquetado-de-alimentos-introduccion/ (accessed October 2016). 
35. Ministério de Saúde, Brasil (2014) Guia Alimentar para a população Brasileira. http://portalarquivos.saude.gov.br/ images/pdf/2014/novembro/05/Guia-Alimentar-para-a-popbrasiliera-Miolo-PDF-Internet.pdf (accessed March 2017).

36. Ministerio de Salud de Uruguay (2016) Guía Alimentaria para la población Uruguaya. http://msp.gub.uy/sites/ default/files/archivos_adjuntos/MS_guia_web.pdf (accessed March 2017).

37. Food and Agriculture Organization of the United Nations, International Fund for Agricultural Development \& World Food Programme (2015) The State of Food Insecurity in the World. Meeting the 2015 International Hunger Targets: Taking Stock of Uneven Progress. Rome: FAO: IFAD and WFP; available at http://www.fao.org/3/a-i4646e.pdf
38. Bingham S, Luben R, Welch A et al. (2007) Epidemiologic assessment of sugars consumption using biomarkers: comparisons of obese and nonobese individuals in the European Prospective Investigation of Cancer Norfolk. Cancer Epidemiol Biomarkers Prev 16, 1651-1654.

39. Lafay L, Mennen L, Basdevant A et al. (2000) Does energy intake underreporting involve all kinds of food or only specific food items? Results from the Fleurbaix Laventie Ville Santé (FLVS) study. Int J Obes Relat Metab Disord 24, 1500-1506.

40. Pryer JA, Vrijheid M, Nichols R et al. (1997) Who are the 'low energy reporters' in the Dietary and Nutritional Survey of British Adults? Int J Epidemiol 26, 146-154. 